\title{
Intravenous Infusion of Apolipoprotein E Accelerates Clearance of Plasma Lipoproteins in Rabbits
}

\author{
Robert W. Mahley, ${ }^{*}$ Karl H. Weisgraber, ${ }^{*}$ M. Mahmood Hussain, ${ }^{*}$ Benjamin Greenman, ${ }^{\ddagger}$ \\ Meir Fisher, ${ }^{\ddagger}$ Tikva Vogel, ${ }^{\ddagger}$ and Marian Gorecki ${ }^{\ddagger}$ \\ * Gladstone Foundation Laboratories for Cardiovascular Disease, Cardiovascular Research Institute, Departments of Pathology and \\ Medicine, University of California, San Francisco, San Francisco, California 94140; and ${ }^{\ddagger}$ Biotechnology General Limited, Rehovot, \\ Israel 76326
}

\begin{abstract}
Plasma cholesterol levels in cholesterol-fed rabbits were markedly reduced by the intravenous infusion or bolus injection of recombinant human apo $E$ or rabbit plasma apo E. Administration of 6-70 mg of apo $E$ resulted in an $\sim 20-40 \%$ acute reduction in plasma cholesterol levels within 2-3 h. Plasma cholesterol levels remained reduced for 4-8 $\mathrm{h}$ after the administration of apo E. Furthermore, the intravenous injection of apo $\mathbf{E}$ reduced the plasma cholesterol levels in Watanabe heritable hyperlipidemic rabbits. The addition of apo $\mathrm{E}$ to $\left[{ }^{14} \mathrm{C}\right] \mathrm{choles}-$ terol-labeled canine thoracic duct lymph or $\left[{ }^{14} \mathrm{C}\right]$ cholesterol-labeled chylomicrons resulted in accelerated plasma clearance of these diet-induced lipoproteins in normal rabbits, with the uptake occurring primarily in the liver. This study suggests that the amount or availability of apo $E$ in the plasma of cholesterol-fed rabbits may be rate limiting for the normal clearance of diet-induced remnant lipoproteins.
\end{abstract}

\section{Introduction}

Apo $\mathrm{E}$ is a $M_{\mathrm{r}}=34,000$ protein that serves as a ligand for the $\mathrm{LDL}$ receptor (also referred to as the apoB, $\mathrm{E}(\mathrm{LDL})$ receptor) (1). Apo $\mathrm{E}$ is a protein constituent of several plasma lipoproteins: chylomicrons, chylomicron remnants, VLDL, intermediate-density lipoproteins, and a subclass of HDL (2). Plasma lipid levels are regulated through the interaction of apo E- and apo B-containing lipoproteins with LDL receptors, which mediate the internalization and degradation of the lipoproteins (especially by liver parenchymal cells). In addition, a unique receptor specific for chylomicron remnants, the so-called apo $\mathrm{E}$ or chylomicron remnant receptor, has been postulated to exist in the liver and to participate in lipoprotein metabolism (1-3).

Cholesterol-fed rabbits develop a hypercholesterolemia that is characterized by an increase in $d<1.006 \mathrm{~g} / \mathrm{ml}$ lipopro-

Address reprint requests to Dr. Robert W. Mahley, Gladstone Foundation Laboratories, P.O. Box 40608, San Francisco, CA 94140-0608.

Received for publication 8 February 1989 and in revised form 27 March 1989.

J. Clin. Invest.

(C) The American Society for Clinical Investigation, Inc.

0021-9738/89/06/2125/06 \$2.00

Volume 83, June 1989, 2125-2130 teins, which are predominantly of intestinal origin (for review, see reference 4$)$. However, in a variety of cholesterol-fed animals, the $d<1.006 \mathrm{~g} / \mathrm{ml}$ lipoproteins ( $\beta$-VLDL) include cholesterol-rich chylomicron remnants and VLDL remnants $(5$, 6). This study was undertaken to determine whether the intravenous delivery of excess apo $\mathrm{E}$ in cholesterol-fed rabbits would result in a lowering of plasma lipid levels. It was postulated that an increase in the delivery of apo $\mathrm{E}$ to the plasma might accelerate the clearance of the remnant lipoproteins, which are known to interact with lipoprotein receptors via apo $\mathrm{E}(1,2)$.

\section{Methods}

\section{Animals and diets}

New Zealand White rabbits (males; typically $2.5-3.5 \mathrm{~kg}$ ) obtained from Animal West (Soquel, CA) were maintained on rabbit chow (Ralston-Purina Co., St. Louis, MO). Cholesterol-fed rabbits received a semipurified diet (700-79; Zeigler Bros., Inc., Gardners, PA) containing $3 \%$ soybean oil and $0.5 \%$ cholesterol as previously described (7). They were maintained on the cholesterol-rich diet for 2-6 wk before use. Watanabe heritable hyperlipidemic rabbits (51/2-6-mo-old males; $2.8-3.2 \mathrm{~kg}$ ) obtained from the National Institutes of Health (Bethesda, MD) were maintained on rabbit chow (Ralston-Purina Co.).

\section{Canine thoracic duct lymph}

Adult mongrel dogs (University of California, San Francisco), maintained under controlled laboratory conditions for $>4 \mathrm{wk}$, were used as a source of lymph. A lymph fistula, prepared as described elsewhere (8), allowed the collection of thoracic duct lymph. Briefly, anesthetized dogs received $\left[4-{ }^{14} \mathrm{C}\right]$ cholesterol $(250 \mu \mathrm{Ci})$ in $5 \mathrm{ml}$ of corn oil by gastric intubation. In addition, they were fed $450 \mathrm{ml}$ of the fat-rich, nondairy creamer Mocha Mix (Presto Food Products, Industry, CA) to which $2.1 \%$ sucrose and $0.2 \%$ cholesterol (by weight) had been added (9). Lymph was collected in blood packs (Fenwal Laboratories, Garden Grove, CA) containing $250 \mathrm{mg}$ of disodium EDTA, 16,000 kallikrein inhibitor units (KIU) of Trasylol, and $167 \mathrm{mg}$ of 5,5'-dithiobis-(2-nitrobenzoic acid) in $5 \mathrm{ml}$ of distilled $\mathrm{H}_{2} \mathrm{O} .100 \mu \mathrm{g} / \mathrm{ml}$ kanamycin, $1 \mathrm{mM}$ PMSF, and $1 \mathrm{mM}$ benzamidine were added to the lymph after collection. The protease inhibitors are those recommended by Edelstein and Scanu (10). This method for stimulating the formation of chylomicrons and collecting the lymph has been used extensively in this laboratory (9). Lymph was incubated for $1 \mathrm{~h}$ at $37^{\circ} \mathrm{C}$ with or without added recombinant apo $\mathrm{E}$ ( $235 \mathrm{mg}$ of triglyceride plus $40 \mathrm{mg}$ of apo $\mathrm{E}$ ). Lymph was infused into normal rabbits for $1 \mathrm{~h}$ at $4 \mathrm{mg}$ of triglyceride/min.

\section{Canine chylomicrons}

Lymph with the highest concentration of radioactivity (usually the lymph collected 4-8 $\mathrm{h}$ after administration of fat) was centrifuged at $28,000 \mathrm{rpm}$ for $90 \mathrm{~min}$ in a rotor (model SW28; Beckman Instruments, Palo Alto, CA) at $20^{\circ} \mathrm{C}$. The layer of chylomicrons was removed, 
resuspended, passed through $0.45-\mu \mathrm{m}$ filters, stored at $4^{\circ} \mathrm{C}$, and used within $2 \mathrm{wk}$. The chylomicrons induced by this procedure and isolated as described have been characterized (9). The chylomicrons were incubated at $37^{\circ} \mathrm{C}$ for $1 \mathrm{~h}$ in the presence or absence of recombinant human apo E (49 $\mathrm{mg}$ of chylomicron triglyceride plus $13.3 \mathrm{mg}$ of apo E).

\section{Apo $E$}

Human recombinant apo E3 has been produced in Escherichia coli, characterized with respect to biological activity, and shown to be identical to plasma apo E3 (11). The receptor binding activity and in vivo clearance rates of the human recombinant apo E used in this study were identical to those previously reported for recombinant apo $E$ and human plasma apo E3 (11). Analysis of the purified recombinant apo E by the Gel-Clot technique (Limulus amebocyte lysate kit; Whittaker M. A. Bioproducts, Walkersville, MD) showed that it contained $<20$ $\mathrm{pg}$ of endotoxin/mg of protein. The recombinant apo E could be concentrated to $\sim 5 \mathrm{mg} / \mathrm{ml}$ (turbidity occurred at higher concentrations).

Rabbit apo E was isolated from the plasma of cholesterol-fed rabbits as described previously for human apo $\mathrm{E}$ (12). The purified rabbit apo $\mathrm{E}$ bound with high affinity to human fibroblasts in vitro. Apo $\mathrm{E}$ was iodinated using the ${ }^{125}$ I Bolton-Hunter reagent (Amersham Corp., Arlington Heights, IL), as described (13). RIA were performed with a solid-phase assay based on that described by Fainaru et al. (14). Human apo $E$ antisera prepared in rabbits detected human apo $E$ but not rabbit apo $E$ in the plasma of normal and cholesterol-fed rabbits.

\section{Intravenous administration of apo $E$}

Protocol 1. Cholesterol-fed rabbits (not fasted) were anesthetized with methoxyflurane and infused through the ear vein with saline for a baseline period of $1 \mathrm{~h}$ at $0.33 \mathrm{ml} / \mathrm{min}$. After this period, $70 \mathrm{mg}$ of recombinant apo $\mathrm{E}$ in saline $(0.15 \mathrm{M} \mathrm{NaCl})$ or saline alone was infused for $2 \mathrm{~h}$ at $0.29 \mathrm{ml} / \mathrm{min}$. We analyzed a zero time blood sample at the end of the baseline period, plus samples at 30-min intervals during the infusion of apo $\mathrm{E}$ or the saline control, for plasma cholesterol and triglyceride. Lipoprotein cholesterol and triglyceride concentrations were determined as described (5).

Protocol 2. In contrast to protocol 1, the cholesterol-fed rabbits were not anesthetized and did not receive a baseline infusion of saline. The rabbits (not fasted) were intravenously infused for $2 \mathrm{~h}$ either with rabbit plasma apo $E(45 \mathrm{mg})$ in saline or with saline alone $(0.1 \mathrm{ml} /$ $\mathrm{min})$, with recombinant apo $\mathrm{E}(41 \mathrm{mg})$ in saline or with saline alone $(0.07 \mathrm{ml} / \mathrm{min})$, or with recombinant apo $\mathrm{E}(33.7 \mathrm{mg})$ in rabbit serum or with autologous rabbit serum alone $(0.1 \mathrm{ml} / \mathrm{min})$. To prepare the apo $\mathrm{E}$ in serum, $7 \mathrm{ml}$ of apo $\mathrm{E}$ in saline was added to $5 \mathrm{ml}$ of freshly prepared rabbit serum (autologous rabbit serum was obtained $16 \mathrm{~h}$ before the study). For plasma cholesterol and triglyceride determinations, blood samples were obtained before the infusion; at 30,75 , and $120 \mathrm{~min}$ during the infusion; and at $\mathbf{4 5} \mathrm{min}$ after the infusion.

Protocol 3. Unanesthetized cholesterol-fed rabbits were given either a bolus intravenous injection (for $60 \mathrm{~s}$ ) of rabbit plasma apo E $(29 \mathrm{mg}$ ) in $6 \mathrm{ml}$ of saline, or $6 \mathrm{ml}$ of saline alone. In separate studies, rabbits were injected with rabbit plasma apo $\mathrm{E}(46.8 \mathrm{mg})$ in $8 \mathrm{ml}$ of saline or with $8 \mathrm{ml}$ of saline alone. Blood samples were obtained for plasma cholesterol and triglyceride determination at zero time (just before bolus injection) and at 5, 30,75, 120, and $165 \mathrm{~min}$ after injection. Rabbits were either fasted overnight or not fasted (see Table IV legend). Other cholesterol-fed rabbits (not fasted) received 6 or $12 \mathrm{mg}$ of recombinant apo $\mathrm{E}$ in $6 \mathrm{ml}$ of saline, or $6 \mathrm{ml}$ of saline alone.

\section{Plasma clearance and tissue distribution}

Blood samples from the ear vein were collected in tubes containing disodium EDTA $(0.1 \% \mathrm{wt} / \mathrm{vol})$. Radioactivity in the plasma was determined in a liquid scintillation counter (Model LS7500; Beckman Instruments) or in a gamma counter (Model Gamma 4000; Beckman Instruments). Plasma volume was estimated to be $3.5 \%$ of body weight. Tissues were immediately collected from rabbits euthanized by a 1-ml injection of Euthanasia (Anthony Products, Arcadia, CA). The liver, spleen, kidney, heart, adrenals, lung, and adipose tissue were rinsed in saline, blotted, and weighed as described (9). Bone marrow was obtained by removing both ends of the femur and tibia and pushing the contents from the shaft with an applicator stick. Bone marrow values represent an average of the uptake by the femur and tibia. The amount of $\left[{ }^{14} \mathrm{C}\right]$ cholesterol uptake was determined by extracting lipids from the tissues as described, and organ weight was calculated as previously reported (9).

\section{Results}

Recombinant human apo E3 produced in bacteria was infused intravenously into cholesterol-fed rabbits under three different protocols. In protocol 1 , anesthetized rabbits were infused with saline $(0.33 \mathrm{ml} / \mathrm{min})$ for $1 \mathrm{~h}$, then with $70 \mathrm{mg}$ of the recombinant apo E3 in saline $(0.29 \mathrm{ml} / \mathrm{min})$ for $2 \mathrm{~h}$. Control animals received a saline infusion for the $2 \mathrm{~h}$. As shown in Table $I$, the cholesterol-fed rabbits receiving the apo $\mathrm{E}$ had a $21-34 \%$ reduction in their plasma cholesterol levels, in contrast to a $10-14 \%$ reduction in the saline-infused controls. These data suggested that the administration of apo $E$ resulted in an accel-

Table I. Response of Cholesterol-fed Rabbits to the Intravenous Infusion of Recombinant Apo E

\begin{tabular}{|c|c|c|c|c|c|c|c|c|}
\hline & \multicolumn{4}{|c|}{ Apo $\mathrm{E}$ infusion } & \multicolumn{4}{|c|}{ Saline control } \\
\hline & T Chol & Trig & T Chol & Trig & T Chol & Trig & T Chol & Trig \\
\hline & \multicolumn{8}{|c|}{$m g / d l$} \\
\hline 0 Time & 1,005 & 50 & 679 & 45 & 695 & 45 & 339 & 62 \\
\hline \multicolumn{9}{|c|}{ Infusion period } \\
\hline $30 \mathrm{~min}$ & 909 & 51 & 640 & 50 & 655 & 46 & 321 & 57 \\
\hline $60 \mathrm{~min}$ & 817 & 60 & 606 & 64 & 650 & 48 & 320 & 54 \\
\hline $90 \mathrm{~min}$ & 721 & 69 & 566 & 72 & 637 & 54 & 306 & 47 \\
\hline $120 \mathrm{~min}$ & 668 & 79 & 535 & 76 & 624 & 60 & 295 & 47 \\
\hline$\%$ Change & -33.5 & & -21.2 & & -10.2 & & -13.5 & \\
\hline
\end{tabular}

See protocol 1 in Methods. Approximately $70 \mathrm{mg}$ of recombinant apo E was infused into two cholesterol-fed rabbits. Two other cholesterol-fed rabbits were infused with saline. Total plasma cholesterol ( $\mathrm{T} \mathrm{Chol)} \mathrm{and} \mathrm{triglyceride} \mathrm{(Trig)} \mathrm{are} \mathrm{reported} \mathrm{as} \mathrm{milligrams/deciliters.}$ 
erated clearance of cholesterol-rich lipoproteins from the plasma. However, the response of the plasma triglycerides was variable.

To investigate the fate of the intravenously administered apo $\mathrm{E}$, an aliquot of the apo $\mathrm{E}$ was iodinated $\left({ }^{125} \mathrm{I}\right)$, mixed with the $70 \mathrm{mg}$ of unlabeled apo $\mathrm{E}$ (final specific activity, 2,990 $\mathrm{cpm} / \mu \mathrm{g}$ ), and infused into cholesterol-fed rabbits under the same protocol as reported in Table I. Based on the specific activity of the injected apo $E$, the quantity of human apo $E$ remaining in the plasma at each time point and the final amount taken up by tissues during the 2-h infusion could be calculated. The two rabbits used in this experiment had initial plasma cholesterol levels of 1,094 and $620 \mathrm{mg} / \mathrm{dl}$; the 2-h infusion of the $70 \mathrm{mg}$ of apo E resulted in 27 and $18 \%$ decreases in plasma cholesterol levels, respectively. Recombinant apo E levels in the plasma of these two cholesterol-fed rabbits rose steadily during almost the entire infusion period (Fig. $1 \mathrm{~A}$ ). Approximately $15-20 \mathrm{mg}$ of infused apo $\mathrm{E}$ remained in the plasma after $2 \mathrm{~h}$; therefore, $\sim 50-55 \mathrm{mg}$ of apo $\mathrm{E}$ was removed from the plasma during the 2-h infusion. At the end of the 2-h infusion, when $\sim 25 \%$ of the injected dose of apo $E$ remained in the plasma, $41-47 \%$ of the injected dose had been taken up by the liver (Fig. $1 \mathrm{~B}$ ). Previously, we have shown that bone marrow in the rabbit takes up a significant quantity of triglyceride-rich lipoproteins (9). However, in the presence of excess apo $\mathrm{E},<10 \%$ of the injected dose was detected in the bone marrow, an observation consistent with previous findings that suggest that apo $\mathrm{E}$ preferentially directs lipoproteins to the liver (9). The $\sim 9-11 \%$ of the injected dose detected in the kidney presumably represented cleared ${ }^{125}$ I-labeled apo $E$ or proteolytic fragments of the ${ }^{125}$ I-labeled apo E. Very low levels of ${ }^{125} \mathrm{I}$ were detected in other organs $(<1 \%$ of the injected dose). In a separate experiment using the same infusion protocol, $\sim 19 \%$ of the injected dose of apo $E$ remained in the plasma at the end of the 2-h infusion. $3 \mathrm{~h}$ later, $13 \%$ of the injected dose of apo E was still in the plasma, and the plasma
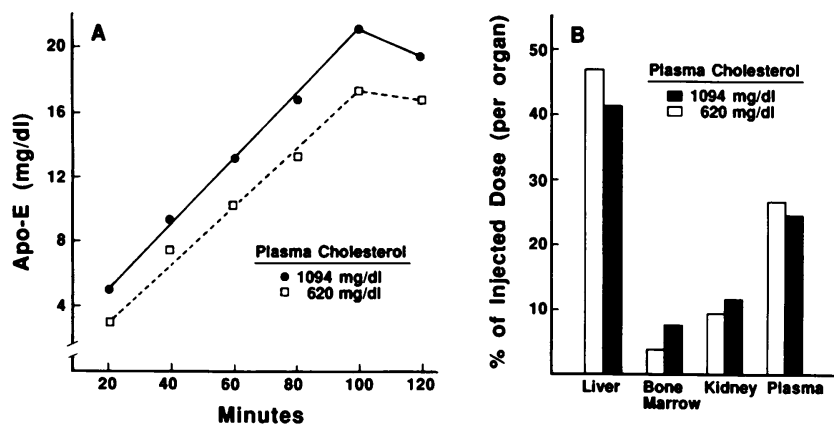

Figure 1. (A) Accumulation of recombinant apo $\mathrm{E}$ in the plasma of cholesterol-fed rabbits. A tracer dose of ${ }^{125} \mathrm{I}$-labeled apo $\mathrm{E}$ was added to $70 \mathrm{mg}$ of unlabeled apo $\mathrm{E}$, and the mixture was infused for $2 \mathrm{~h}$ into two cholesterol-fed rabbits. The quantity (in milligrams/deciliter) of recombinant apo $\mathrm{E}$ that accumulated in the plasma was calculated on the basis of the specific activity of the apo $E$ injected. The initial plasma cholesterol levels in the rabbits are indicated in the figure. $(B)$ Distribution of ${ }^{125} \mathrm{I}$-labeled apo $\mathrm{E}$ in the tissues and plasma. The percentage of the injected dose of ${ }^{125}$ I-labeled apo E that accumulated in the tissues (per organ) or that remained in the plasma at the end of the 2-h infusion is shown for both rabbits. The spleen and lung in both animals each possessed $<2 \%$ of the injected dose, and the adrenals, heart muscle, and adipose tissue each had $<0.1 \%$. cholesterol level in this cholesterol-fed rabbit had decreased by $35.3 \%$. From these studies it appears that the infusion of apo $\mathrm{E}$ results in the clearance of cholesterol-rich lipoproteins, primarily by the liver.

As shown in Table I, the saline control rabbits also had a reduction in plasma cholesterol levels. Because the reduction might have been due to plasma dilution secondary to saline infusion, an effect of the anesthesia, or both, unanesthetized cholesterol-fed rabbits were infused with apo $E$ in smaller fluid volumes (protocol 2). Approximately $40 \mathrm{mg}$ of recombinant apo $\mathrm{E}$ in saline or in autologous rabbit serum was administered for a 2 -h period, followed by a 45 -min postinfusion period. As a result, the decrease in the plasma cholesterol levels in the saline or serum controls was minimized (to 4-6\%), whereas apo $\mathrm{E}$ infusion resulted in a $26-27 \%$ reduction in plasma cholesterol (Table II). Therefore, it was possible to reduce, but not eliminate, this experimental effect on the control animals; as will be seen in other experiments, some rabbits do appear to be highly sensitive to the injection of rather small volumes of fluid, necessitating parallel control studies. However, apo E can only be concentrated to $\sim 5 \mathrm{mg} / \mathrm{ml}$ without forming visible aggregates, thus limiting the amount of apo $E$ that can be administered.

To determine whether rabbit plasma apo $\mathrm{E}$ had an effect similar to recombinant apo $\mathrm{E}$ in reducing plasma lipids, $45 \mathrm{mg}$ of rabbit apo $E$ was administered $(0.1 \mathrm{ml} / \mathrm{min})$ to a cholesterol-fed rabbit. The plasma cholesterol decreased by $39 \%$ at the end of the 2-h infusion period and by $37 \%$ at $45 \mathrm{~min}$ after the infusion period (Table III). The plasma triglyceride level was decreased at $30 \mathrm{~min}$ after the apo $\mathrm{E}$ infusion began; however, it approached the zero time control value by $45 \mathrm{~min}$ after infusion. The cholesterol levels in the saline control were essentially unchanged.

As an alternative method for administering apo $\mathrm{E}$ (protocol 3 ), a bolus intravenous injection of apo $E$ was given to a cholesterol-fed, unanesthetized rabbit. Rabbit plasma apo E (29

Table II. Effect of the Intravenous Infusion of Recombinant Apo E in Saline or Serum on Plasma Cholesterol Levels in Cholesterol-fed Rabbits

\begin{tabular}{|c|c|c|c|c|}
\hline & \multicolumn{2}{|c|}{ Infusion in saline* } & \multicolumn{2}{|c|}{ Infusion in serum ${ }^{\ddagger}$} \\
\hline & Apo $\mathrm{E}$ & Control & Apo $E$ & Control \\
\hline & \multicolumn{4}{|c|}{$m g / d l$} \\
\hline 0 Time & 320 & 815 & 769 & 736 \\
\hline \multicolumn{5}{|c|}{ Infusion period } \\
\hline $30 \mathrm{~min}$ & 289 & 782 & 705 & 669 \\
\hline $75 \mathrm{~min}$ & 268 & 780 & 651 & 695 \\
\hline $120 \mathrm{~min}$ & 251 & 736 & 623 & 706 \\
\hline \multicolumn{5}{|c|}{ Postinfusion period } \\
\hline $45 \mathrm{~min}$ & 235 & 780 & 573 & 693 \\
\hline$\%$ Change & -26.6 & -4.3 & -25.5 & -5.8 \\
\hline
\end{tabular}

See protocol 2 in Methods. Plasma cholesterol is reported as milligrams/deciliter.

* Recombinant apo E (41 mg) in saline or saline alone (control) was infused at $0.07 \mathrm{ml} / \mathrm{min}$.

${ }^{\ddagger}$ Recombinant apo E $(33.7 \mathrm{mg})$ in rabbit serum or rabbit serum alone (control) was infused at $0.1 \mathrm{ml} / \mathrm{min}$. Autologous rabbit serum was prepared $16 \mathrm{~h}$ before the injection. 
Table III. Effect of Rabbit Plasma Apo E on Plasma Cholesterol and Triglyceride Levels in Cholesterol-fed Rabbits

\begin{tabular}{|c|c|c|c|}
\hline & \multicolumn{2}{|c|}{ Apo $E$ infusion } & \multirow{2}{*}{$\frac{\text { Saline control }}{\text { Total cholesterol }}$} \\
\hline & Total cholesterol & Triglyceride & \\
\hline 0 Time & 1,030 & $\begin{array}{c}m g / d l \\
108\end{array}$ & 774 \\
\hline \multicolumn{4}{|l|}{ Infusion period } \\
\hline $30 \mathrm{~min}$ & 737 & 85 & 806 \\
\hline $75 \mathrm{~min}$ & 713 & 85 & 778 \\
\hline $120 \mathrm{~min}$ & 625 & 92 & 776 \\
\hline \multicolumn{4}{|l|}{ Postinfusion period } \\
\hline $45 \mathrm{~min}$ & 653 & 98 & 787 \\
\hline \multicolumn{4}{|l|}{$\%$ Change } \\
\hline End of infusion & -39.3 & & $\sim 0$ \\
\hline End of postinfusion period & -36.6 & & +1.7 \\
\hline
\end{tabular}

See protocol 2 in Methods. Rabbit apo E (45 mg) in saline or saline alone (control) was infused at $0.1 \mathrm{ml} / \mathrm{min}$. Plasma cholesterol and triglyceride levels are reported as milligrams/deciliter.

$\mathrm{mg}$ in $6 \mathrm{ml}$ of saline, rabbit I; $46.8 \mathrm{mg}$ in $8 \mathrm{ml}$, rabbit II) resulted in a $37-38 \%$ reduction in plasma cholesterol levels in two cholesterol-fed rabbits (Table IV). However, in rabbit I the plasma triglyceride decreased in parallel with the cholesterol, whereas the triglyceride levels in rabbit II actually increased after an initial decrease. This variability appears to correlate with the induction of VLDL biosynthesis after the delivery of a large dose of remnant lipoproteins to the liver in rabbits (see Discussion). The plasma cholesterol levels of the saline controls (rabbits III and IV) decreased by $11-12 \%$.

Table IV. Effect of a Bolus Intravenous Injection of Rabbit Plasma Apo E on the Plasma Cholesterol and Triglyceride Levels in Cholesterol-fed Rabbits

\begin{tabular}{|c|c|c|c|c|c|c|}
\hline & \multicolumn{4}{|c|}{ Apo $\mathrm{E}$ infusion } & \multirow{2}{*}{\multicolumn{2}{|c|}{$\begin{array}{c}\text { Saline control } \\
\text { Total cholesterol }\end{array}$}} \\
\hline & \multicolumn{2}{|c|}{ Total cholesterol } & \multicolumn{2}{|c|}{ Triglyceride } & & \\
\hline & I & II & I & II & III & IV \\
\hline & \multicolumn{6}{|c|}{$m g / d l$} \\
\hline 0 Time & 617 & 1,118 & 152 & 176 & 1,070 & 1,295 \\
\hline \multicolumn{7}{|c|}{ Bolus injection } \\
\hline $5 \mathrm{~min}$ & 567 & - & 139 & - & 974 & - \\
\hline $30 \mathrm{~min}$ & 472 & 805 & 142 & 146 & 1,010 & 1,159 \\
\hline $75 \mathrm{~min}$ & 427 & 737 & 113 & 143 & 936 & 1,145 \\
\hline $120 \mathrm{~min}$ & 425 & - & 104 & - & 948 & 1,136 \\
\hline $165 \mathrm{~min}$ & 392 & 694 & 101 & 210 & 951 & 1,125 \\
\hline$\%$ Change & -36.5 & -38.0 & & & -11.1 & -12 \\
\hline
\end{tabular}

See protocol 3 in Methods. Study rabbit I, rabbit apo E ( $29 \mathrm{mg})$ in 6 $\mathrm{ml}$ of saline injected as a bolus; study rabbit II, rabbit apo E $(46.8$ $\mathrm{mg}$ ) in $8 \mathrm{ml}$ of saline; study rabbit III, $6 \mathrm{ml}$ of saline; and study rabbit IV, $8 \mathrm{ml}$ of saline. Plasma cholesterol and triglyceride levels are reported as milligrams/deciliter. Rabbits I and III were not fasted; rabbits II and IV were fasted overnight before the study.
The effects of lower doses of apo $E$ and the time course of response of the plasma cholesterol levels to these lower doses were also examined in cholesterol-fed rabbits. As shown in Table $\mathrm{V}$, a bolus intravenous injection of recombinant apo $\mathrm{E}$ at a dose of 6 or $12 \mathrm{mg}$ resulted in a marked reduction in the plasma cholesterol levels for 4-8 $\mathrm{h}$. However, the plasma cholesterol levels returned to at least pretreatment values at $24 \mathrm{~h}$ after apo $\mathrm{E}$ infusion.

In additional studies, a bolus injection of apo $\mathrm{E}(38 \mathrm{mg}$ of recombinant apo $\mathrm{E}$ ) was administered to two unanesthetized Watanabe heritable hyperlipidemic rabbits (initial plasma cholesterol levels, 533 and $374 \mathrm{mg} / \mathrm{dl}$ ). The plasma cholesterol levels were decreased by $23 \%$ in both animals at $4 \mathrm{~h}$ after apo $\mathrm{E}$ injection. These data are consistent with the recent publication of Yamada et al. (15).

To determine the effect of excess apo $\mathrm{E}$ on the metabolism of diet-induced lipoproteins, $\left[{ }^{14} \mathrm{C}\right]$ cholesterol-labeled intestinal lipoproteins in canine thoracic duct lymph, induced by dietary fat and cholesterol, were injected intravenously into normal fasted rabbits with or without the addition of recombinant apo E. As shown in Fig. $2 A$, incubation of whole lymph with apo $\mathrm{E}$ resulted in a marked acceleration of the clearance of the $\left[{ }^{14} \mathrm{C}\right]$ cholesterol-labeled lipoproteins, especially during the initial period of infusion. The human apo $\mathrm{E}$ level, as determined by a RIA that detected only the human apo $E$, increased in the plasma during the infusion period and then decreased (Fig. 2 $B$ ). The accumulation of apo $\mathrm{E}$ during the infusion undoubtedly reflects a saturation of the clearance mechanism. These data indicate that the amount or availability of apo $E$ in the rabbit may be rate limiting in the processing and/or clearance of intestinal lipoproteins and that the addition of excess apo $\mathrm{E}$ accelerated the initial rate of clearance of the intestinal lipoproteins.

The effect of added apo $\mathrm{E}$ was more dramatic when added to chylomicrons isolated from the canine thoracic duct lymph.

Table V. Effect of a Bolus Intravenous Injection of Recombinant Apo E on the Plasma Cholesterol Levels in Cholesterol-fed Rabbits

\begin{tabular}{|c|c|c|c|c|c|c|}
\hline & \multicolumn{4}{|c|}{ Apo $\mathrm{E}$ infusion } & \multicolumn{2}{|c|}{ Saline control } \\
\hline & \multicolumn{2}{|c|}{$12 \mathrm{mg}$} & \multicolumn{2}{|c|}{$6 \mathrm{mg}$} & \multirow[b]{2}{*}{ I } & \multirow[b]{2}{*}{ II } \\
\hline & I & II & $\mathbf{I}$ & II & & \\
\hline Plasma cholesterol $(m g / d l)^{*}$ & 402 & 519 & 217 & 315 & 427 & 259 \\
\hline \multicolumn{7}{|l|}{$\%$ Change $^{\ddagger}$} \\
\hline $2 \mathrm{~h}$ & -39 & -32 & -19 & -19 & -4 & +1 \\
\hline $4 \mathrm{~h}$ & -42 & -32 & -22 & -23 & -8 & +6 \\
\hline $8 \mathrm{~h}$ & - & -32 & - & -26 & - & +3 \\
\hline $24 \mathrm{~h}^{\S}$ & - & +17 & - & +6 & - & +27 \\
\hline
\end{tabular}

Recombinant apo E (12 or $6 \mathrm{mg}$ ) was injected intravenously as a bolus in $6 \mathrm{ml}$ of saline. Saline control rabbits received $6 \mathrm{ml}$ of saline. * Plasma cholesterol levels are reported as milligrams/deciliter at zero time (just before the injection of apo E).

₹ Percent change in the plasma cholesterol levels after the intravenous injection of apo $\mathrm{E}$ or saline as compared with the zero time values.

${ }^{8}$ After the 8-h blood sample was taken the rabbits were allowed access to the high-fat-high-cholesterol chow and thus were not fasting at the 24-h sample. 

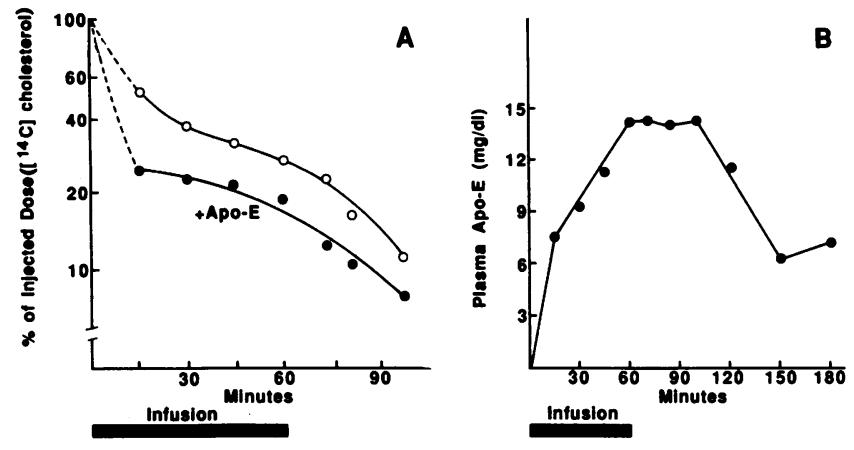

Figure 2. Whole canine thoracic duct lymph containing $\left[{ }^{14} \mathrm{C}\right]$ cholesterol-labeled intestinal lipoproteins was infused intravenously into two normal rabbits at $4 \mathrm{mg} / \mathrm{min}$ for $1 \mathrm{~h}$. One rabbit received whole lymph that had been incubated with recombinant apo E ( $235 \mathrm{mg}$ of lipoprotein triglyceride plus $40 \mathrm{mg}$ of apo E) (๑), whereas the other rabbit received an equal amount of the same lymph that had been incubated without added apo $\mathrm{E}(0)$. $(A)$ The effect of the presence or absence of added apo $\mathrm{E}$ on the plasma clearance of $\left[{ }^{14} \mathrm{C}\right]$ cholesterollabeled whole lymph lipoproteins in normal rabbits (expressed as percentage of injected dose cleared from the plasma). $(B)$ The accumulation of recombinant apo $\mathrm{E}$ in the plasma of the animal receiving the whole lymph plus added apo E, as determined by RIA. The assay, performed using a rabbit antibody to human apo $\mathrm{E}$, detected the recombinant apo $\mathrm{E}$ infused into the rabbit (not the rabbit apo $\mathrm{E}$ ).

The $\left[{ }^{14} \mathrm{C}\right]$ cholesterol-labeled chylomicrons were incubated for $1 \mathrm{~h}$ at $37^{\circ} \mathrm{C}$ in the presence or absence of recombinant apo $\mathrm{E}$ (49 mg of chylomicron triglyceride plus $13.3 \mathrm{mg}$ of apo E/ $\mathrm{kg}$ of body weight). As shown in Fig. $3 \mathrm{~A}$, the addition of apo $\mathrm{E}$ markedly increased the clearance of the $\left[{ }^{14} \mathrm{C}\right]$ cholesterol-labeled chylomicrons from the plasma of a normal rabbit. The uptake of the chylomicrons without added apo $\mathrm{E}$ at $20 \mathrm{~min}$ was primarily by the liver $(\sim 30 \%$ of the injected dose $)$ and the bone marrow $(\sim 40 \%)$ (Fig. $3 B$ ). These results are consistent
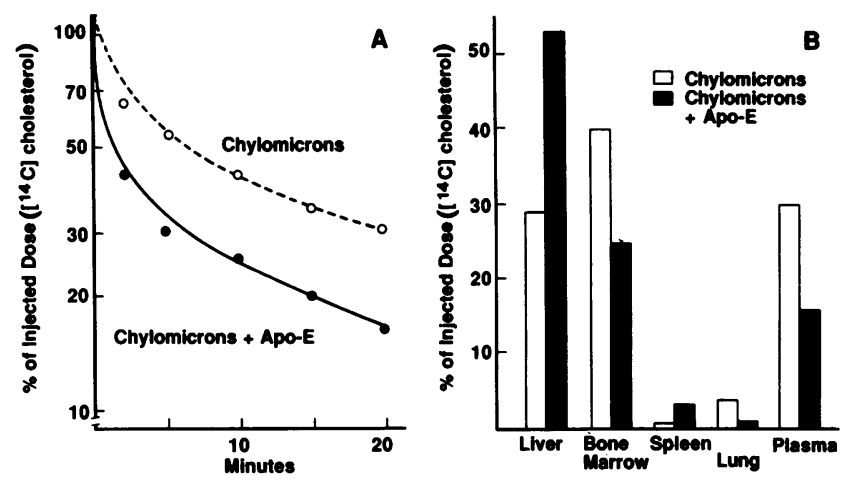

Figure 3. Plasma clearance and tissue uptake of $\left[{ }^{14} \mathrm{C}\right]$ cholesterol-labeled chylomicrons and chylomicrons plus apo $\mathrm{E}$ in normal rabbits (fasted overnight). The $\left[{ }^{14} \mathrm{C}\right]$ cholesterol-labeled chylomicrons isolated from canine thoracic duct lymph were incubated at $37^{\circ} \mathrm{C}$ in the absence or presence of recombinant apo E $(49 \mathrm{mg}$ of chylomicron triglyceride and $0.54 \mathrm{mg}$ of chylomicron cholesterol $/ \mathrm{kg}$ of body weight, plus $13.3 \mathrm{mg}$ of apo E) for $1 \mathrm{~h}$ and then were injected intravenously into the rabbits. $(A)$ Plasma clearance of the chylomicrons $(O)$ or chylomicrons plus apo $\mathrm{E}(\bullet)$. (B) Tissue uptake calculated as the percentage of injected dose of $\left[{ }^{14} \mathrm{C}\right]$ cholesterol recovered in the tissues at $20 \mathrm{~min}$. Other tissues analyzed (adrenal, kidney, heart muscle, and adipose tissue) each contained $<1 \%$ of the injected dose. with recent data from this laboratory (9). When apo $\mathrm{E}$ was added to the $\left[{ }^{14} \mathrm{C}\right]$ cholesterol-labeled chylomicrons, the liver accounted for $53 \%$ of the clearance from the plasma, and the bone marrow accounted for $25 \%$, indicating that the addition of apo $\mathrm{E}$ preferentially directs these lipoproteins to the liver for uptake.

\section{Discussion}

The intravenous infusion or bolus injection of recombinant human apo $E$ or rabbit plasma apo $E$ at doses of $6-70 \mathrm{mg}$ of protein per rabbit markedly lowered the plasma cholesterol levels in cholesterol-fed rabbits in these acute studies (2-3 h). Plasma cholesterol levels remained reduced for up to 4-8 h after the administration of apo $\mathrm{E}$. The intravenously administered apo $\mathrm{E}$ (labeled by a tracer dose of ${ }^{125} \mathrm{I}$-apo $\mathrm{E}$ ) was cleared from the plasma predominantly by the liver. Smaller quantities appeared in the bone marrow and the kidney. Recently, the perisinusoidal macrophages in rabbit bone marrow have been shown to take up chylomicrons and chylomicron remnants (9). Presumably the uptake by the kidney represents the clearance of free ${ }^{125}$ I-labeled apo E or small ${ }^{125}$ I-labeled peptides. Therefore, these data are interpreted as demonstrating that the administration of excess apo $\mathrm{E}$ to rabbits facilitates the hepatic clearance of cholesterol-rich lipoproteins, most likely the cholesterol-induced $\beta$-VLDL (chylomicron and VLDL remnants).

This study also demonstrates that the addition of apo $\mathrm{E}$ to intestinal lipoproteins accelerates their plasma clearance. Diet-induced $\left[{ }^{14} \mathrm{C}\right]$ cholesterol-labeled lipoproteins in canine thoracic duct lymph incubated with apo $\mathrm{E}$ were more rapidly removed from the plasma than those without apo E. Furthermore, the addition of apo $\mathrm{E}$ to isolated $\left[{ }^{14} \mathrm{C}\right]$ cholesterol-labeled chylomicrons increased their plasma clearance and approximately doubled the quantity of chylomicrons taken up by the liver.

The variable response of the plasma triglyceride levels of the cholesterol-fed rabbits to the infusion of apo $E$ was initially puzzling. In some cases the triglyceride levels appeared to decrease with apo $\mathrm{E}$ infusion, whereas in others they increased. Although diet-induced hyperlipoproteinemia is characterized almost exclusively by elevated cholesterol levels, one would assume that if apo $\mathrm{E}$ was accelerating the clearance of remnant lipoproteins, the triglyceride levels would decrease along with the cholesterol levels. However, we have recently observed that the delivery of large quantities of chylomicron remnants to the liver of rabbits appears to result in a rapid, marked acceleration in the production of very large VLDL (which presumably are triglyceride rich) by hepatocytes at variable time intervals after injection of the remnants (Boyles, J. K., R. W. Mahley, and $M$. M. Hussain, unpublished data). These data are consistent with the observation that rat chylomicron remnants and $\beta$-VLDL can induce the secretion of large quantities of VLDL by the transformed human liver cell line, HepG2 (16). Therefore, we interpret the variable response of the plasma triglyceride to apo $E$ infusion to reflect the simultaneous occurrence of two competing processes, i.e., the enhanced uptake of remnant lipoproteins and the induction of a variable amount of VLDL secretion. In some rabbits there appears to be a prompt induction of VLDL synthesis (Table I, high levels of apo E infused), whereas there may be no induction at a lower concentration of apo E (Table IV, rabbit I). On the other hand, there could be 
an initial decrease in plasma triglyceride, followed by a prompt rise (Table IV, rabbit II). Studies are in progress to determine the contribution of these two competing processes in response to high levels of apo E administration.

This study suggests that the amount or availability of apo E may limit the rate of cholesterol uptake in cholesterol-fed animals and that excess apo $\mathrm{E}$ promotes a decrease in plasma cholesterol in cholesterol-fed and Watanabe heritable hyperlipidemic rabbits, presumably by accelerating the hepatic clearance of remnant lipoproteins. Clearly, apo $\mathrm{E}$ was given in high doses in this study to maximize the effect. Normal rabbits have apo E levels of $\sim 2-2.5 \mathrm{mg} / \mathrm{dl}$ (17), whereas cholesterol feeding of Watanabe heritable hyperlipidemic rabbits (plasma cholesterol $\approx 1,200 \mathrm{mg} / \mathrm{dl}$ ) can result in apo E levels of $\sim 33$ $\mathrm{mg} / \mathrm{dl}$ (17). The availability of additional apo $\mathrm{E}$ to associate with the lipoprotein particles could enhance the binding affinity of these lipoproteins to hepatic lipoprotein receptors, resulting in a greater uptake: apo E-containing lipoproteins bind to LDL receptors with a 20-25-fold greater affinity than do LDL $(2,18)$. This enhanced binding is mediated by the interaction between multiple apo $E$ molecules on the surface of the lipoproteins with $\mathrm{LDL}$ receptors $(2,18)$. Alternatively, the presence of excess apo E may enhance clearance of plasma lipoproteins, especially remnant lipoproteins, by accelerating the processing of lipoproteins through the action of lipoprotein lipase, lipid transfer proteins, and/or other processes that cause the particles to be recognized more readily by lipoprotein receptors. Although levels of $6 \mathrm{mg}$ of apo E per rabbit markedly reduced the cholesterol levels, the minimum level of apo $\mathrm{E}$ required to have an effect on lipoprotein metabolism will require further study. In addition, the mechanism of action of apo $\mathrm{E}$ injected intravenously needs to be better understood.

\section{Acknowledgments}

The authors thank Walter J. Brecht, Yvonne M. Newhouse, and Peter A. Lindquist for excellent technical assistance. In addition, we appreciate the contributions of Stanley C. Rall, Jr., Ruth Lifshitz, Danny Bartfield, and Rachel Guy. The authors thank Sylvia Richmond for manuscript preparation, Al Averbach and Sally Gullatt Seehafer for editorial assistance, and Charles Benedict and Tom Rolain for graphics.

This work was supported in part by grant HL-28178 from the National Institutes of Health.

\section{References}

1. Mahley, R. W. 1988. Apolipoprotein E: cholesterol transport protein with expanding role in cell biology. Science (Wash. DC). 240:622-630.

2. Mahley, R. W., T. L. Innerarity, S. C. Rall, Jr., and K. H. Weisgraber. 1984. Plasma lipoproteins: apolipoprotein structure and function. J. Lipid Res. 25:1277-1294.

3. Brown, M. S., and J. L. Goldstein. 1983. Lipoprotein receptors in the liver. Control signals for plasma cholesterol traffic. J. Clin. Invest. 72:743-747.

4. Zilversmit, D. B. 1979. Atherogenesis: a postprandial phenomenon. Circulation. 60:473-485.

5. Fainaru, M., R. W. Mahley, R. L. Hamilton, and T. L. Innerarity. 1982. Structural and metabolic heterogeneity of $\beta$-very low density lipoproteins from cholesterol-fed dogs and from humans with Type III hyperlipoproteinemia. J. Lipid Res. 23:702-714.

6. Kane, J. P., G. C. Chen, R. L. Hamilton, D. A. Hardman, M. J. Malloy, and R. J. Havel. 1983. Remnants of lipoproteins of intestinal and hepatic origin in familial dysbetalipoproteinemia. Arteriosclerosis. 3:47-56.

7. Mahley, R. W., T. L. Innerarity, M. S. Brown, Y. K. Ho, and J. L. Goldstein. 1980. Cholesteryl ester synthesis in macrophages: stimulation by $\beta$-very low density lipoproteins from cholesterol-fed animals of several species. J. Lipid Res. 21:970-980.

8. Melchior, G. W., R. W. Mahley, and D. K. Buckhold. 1981. Chylomicron metabolism during dietary-induced hypercholesterolemia in dogs. J. Lipid Res. 22:598-609.

9. Hussain, M. M., R. W. Mahley, J. K. Boyles, M. Fainaru, W. J. Brecht, and P. A. Lindquist. 1989. Chylomicron-chylomicron remnant clearance by liver and bone marrow in rabbits. Factors that modify tissue-specific uptake. J. Biol. Chem. 264:9571-9582.

10. Edelstein, C., and A. M. Scanu. 1986. Precautionary measures for collecting blood destined for lipoprotein isolation. Methods Enzymol. 128:151-155.

11. Vogel, T., K. H. Weisgraber, M. I. Zeevi, H. Ben-Artzi, A. Z. Levanon, S. C. Rall, Jr., T. L. Innerarity, D. Y. Hui, J. M. Taylor, D. Kanner, Z. Yavin, B. Amit, H. Aviv, M. Gorecki, and R. W. Mahley. 1985. Human apolipoprotein E expression in Escherichia coli: structural and functional identity of the bacterially produced protein with plasma apolipoprotein E. Proc. Natl. Acad. Sci. USA. 82:8696-8700.

12. Rall, S. C., Jr., K. H. Weisgraber, and R. W. Mahley. 1986. Isolation and characterization of apolipoprotein E. Methods Enzymol. 128:273-287.

13. Innerarity, T. L., R. E. Pitas, and R. W. Mahley. 1986. Lipoprotein-receptor interactions. Methods Enzymol. 129:542-566.

14. Fainaru, M., R. J. Havel, and K. Imaizumi. 1977. Radioimmunoassay of arginine-rich apolipoprotein of rat serum. Biochim. Biophys. Acta. 490:144-155.

15. Yamada, N., H. Shimano, H. Mokuno, S. Ishibashi, T. Gotohda, M. Kawakami, Y. Watanabe, Y. Akanuma, T. Murase, and F. Takaku. 1989. Increased clearance of plasma cholesterol after injection of apolipoprotein $\mathrm{E}$ into Watanabe heritable hyperlipidemic rabbits. Proc. Natl. Acad. Sci. USA. 86:665-669.

16. Craig; W. Y., R. Nutik, and A. D. Cooper. 1988. Regulation of apoprotein synthesis and secretion in the human hepatoma Hep G2. The effect of exogenous lipoprotein. J. Biol. Chem: 263:13880-13890.

17. Havel, R. J., T. Kita, L. Kotite, J. P. Kane, R. L. Hamilton, J. L. Goldstein, and M. S. Brown. 1982. Concentration and composition of lipoproteins in blood plasma of the WHHL rabbit. An animal model of human familial hypercholesterolemia. Arteriosclerosis. 2:467-474.

18. Mahley, R. W., T. L. Innerarity, K. H. Weisgraber, S. C. Rail, Jr., D. Y. Hui, A. Lalazar, J. K. Boyles, J. M. Taylor, and B. LevyWilson. 1986. Cellular and molecular biology of lipoprotein metabolism: characterization of lipoprotein receptor-ligand interactions. Cold Spring Harbor Symp. Quant. Biol. 51:821-828. 